\title{
How do nitrogen and phosphorus deficiencies affect strigolactone production and exudation?
}

\author{
Kaori Yoneyama $\cdot$ Xiaonan Xie $\cdot$ Hyun Il Kim • \\ Takaya Kisugi $\cdot$ Takahito Nomura . \\ Hitoshi Sekimoto $\cdot$ Takao Yokota $\cdot$ Koichi Yoneyama
}

Received: 23 August 2011/Accepted: 30 November 2011/Published online: 20 December 2011

(C) The Author(s) 2011. This article is published with open access at Springerlink.com

\begin{abstract}
Plants exude strigolactones (SLs) to attract symbiotic arbuscular mycorrhizal fungi in the rhizosphere. Previous studies have demonstrated that phosphorus (P) deficiency, but not nitrogen $(\mathrm{N})$ deficiency, significantly promotes SL exudation in red clover, while in sorghum not only P deficiency but also N deficiency enhances SL exudation. There are differences between plant species in SL exudation under $\mathrm{P}$ - and $\mathrm{N}$-deficient conditions, which may possibly be related to differences between legumes and non-legumes. To investigate this possibility in detail, the effects of $\mathrm{N}$ and $\mathrm{P}$ deficiencies on SL exudation were examined in Fabaceae (alfalfa and Chinese milk vetch), Asteraceae (marigold and lettuce), Solanaceae (tomato), and Poaceae (wheat) plants. In alfalfa as expected, and unexpectedly in tomato, only $\mathrm{P}$ deficiency promoted SL exudation. In contrast, in Chinese milk vetch, a leguminous plant, and in the other non-leguminous plants examined, $\mathrm{N}$ deficiency as well as P deficiency enhanced SL exudation. Distinct reductions in shoot $\mathrm{P}$ levels were observed in plants grown under $\mathrm{N}$ deficiency, except for tomato, in which shoot $\mathrm{P}$ level was increased by $\mathrm{N}$ starvation,
\end{abstract}

K. Yoneyama $\cdot$ X. Xie $\cdot$ H. I. Kim - T. Kisugi - T. Nomura

K. Yoneyama $(\varangle)$

Weed Science Center, Utsunomiya University, 350 Mine-machi,

Utsunomiya 321-8505, Japan

e-mail: yoneyama@cc.utsunomiya-u.ac.jp

H. Sekimoto

Faculty of Agriculture, Utsunomiya University,

350 Mine-machi, Utsunomiya 321-8505, Japan

T. Yokota

Department of Biosciences, Faculty of Science and Technology,

Teikyo University, 1-1, Toyosatodai,

Utsunomiya 320-8851, Japan suggesting that the $\mathrm{P}$ status of the shoot regulates $\mathrm{SL}$ exudation. There seems to be a correlation between shoot $\mathrm{P}$ levels and SL exudation across the species/families investigated.

Keywords Nitrogen deficiency · Phosphorus deficiency · Shoot phosphorus status $\cdot$ Strigolactone

\begin{tabular}{|c|c|}
\hline \multicolumn{2}{|c|}{ Abbreviations } \\
\hline AM & Arbuscular mycorrhizal \\
\hline LC-MS/MS & $\begin{array}{l}\text { High performance liquid chromatography/ } \\
\text { tandem mass spectrometry }\end{array}$ \\
\hline MRM & Multiple reaction monitoring \\
\hline $\mathrm{N}$ & Nitrogen \\
\hline $\mathrm{P}$ & Phosphorus \\
\hline PR & Primary root \\
\hline SL & Strigolactone \\
\hline
\end{tabular}

\section{Introduction}

Among mineral nutrients, plants require greater amounts of nitrogen $(\mathrm{N})$ than of any other mineral nutrients, except for oxygen, carbon, and hydrogen. $\mathrm{N}$ availability is therefore a major factor limiting plant growth in natural environments (Epstein and Bloom 2005). Phosphorus (P) is also a major limiting nutrient because of its low mobility in soil, and plants may face $\mathrm{P}$ deficiency even in fertile soils. One of the important plant strategies for acquiring $\mathrm{N}$ and particularly $\mathrm{P}$ is to form symbiotic relationships with arbuscular mycorrhizal (AM) fungi. Plant-AM fungus symbioses are extremely ancient and more than $80 \%$ of land plants form AM symbioses (Smith and Read 2008). Using fine external hyphae, AM fungi absorb mineral nutrients from the soil 
outside the rhizosphere and translocate them to the host plants. In turn, AM fungi obtain photosynthates from the host plants.

Following spore germination of AM fungi, their hyphae use carbohydrate and lipid reserves and grow, with some nuclear division, to produce a coenocytic mycelium with limited branching (Smith and Read 2008). An intensive hyphal branching in response to host recognition can be induced by a group of chemicals called "strigolactones" (SLs) that are released from plant roots. 5-Deoxystrigol was the first SL isolated as a branching factor from root exudates of Lotus japonicus (Akiyama et al. 2005). Sorgolactone, another SL secreted from the roots of Sorghum bicolor, was found to induce a rapid increase in mitochondrial density and changes in the shape and movement of organelles in AM fungi (Besserer et al. 2006).

SLs were originally identified as germination stimulants for the seeds of the root parasitic plants, Striga spp. and Orobanche spp. Striga and Orobanche parasitize the roots of host plants, deprive water and nutrients from hosts, and consequently negatively affect the growth of host plants. Since the seeds of these root parasites can germinate only when they perceive SLs, it seems that root parasitic plants take advantage of SL as a host recognition signal that plants secrete for commencing symbiotic relationships with AM fungi.

In a previous study we demonstrated that in red clover $\mathrm{P}$ deficiency enhances the exudation of orobanchol, one of the major SLs exuded by this plant (Yoneyama et al. 2007a), whereas in sorghum, $\mathrm{N}$ deficiency as well as $\mathrm{P}$ deficiency promotes the exudation and increased root levels of 5-deoxystrigol (Yoneyama et al. 2007b). P deficiency has been reported to enhance SL production in tomato (López-Ráez et al. 2008). In rice plants, P deficiency (Umehara et al. 2010) as well as N deficiency (Jamil et al. 2011) was shown to promote SL exudation. These different responses of SL exudation to nutrient availability seem to be related to plants' nutrient acquisition strategies. The structures of orobanchol and orobanchyl acetate have been revised recently as shown in Fig. 1 (Ueno et al. 2011).

To date, most research regarding $\mathrm{N}$ acquisition by plants has been focused on the association of legume root nodules with bacteria, whereas the importance of AM fungus-plant symbiosis has been mainly remarked on in the context of $\mathrm{P}$ uptake. However, AM fungi supply $\mathrm{N}$ as well as $\mathrm{P}$ to host plants (Ames et al. 1983; Johansen et al. 1996; Jin et al. 2005). Isotope labeling experiments revealed that AM fungi take up nitrate and ammonium; assimilated arginine is then translocated from the extraradical to the intraradical mycelium, and finally ammonium is transferred to the host plant (Govindarajulu et al. 2005). Therefore, AM symbiosis may play a much more significant role in the global $\mathrm{N}$



Orobanchol

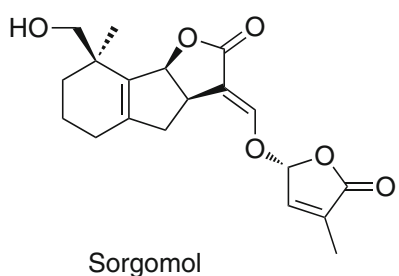

Sorgomol



Orobanchyl acetate

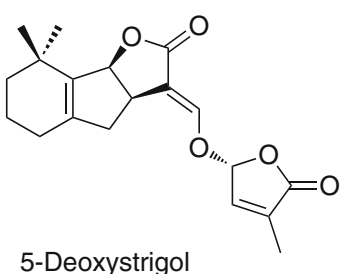

5-Deoxystrigol
Fig. 1 Chemical structures of strigolactones quantified in this study

cycle than has so far been widely believed (Smith and Read 2008). We hypothesize that, in leguminous plants, which have a symbiotic relationship with root nodule bacteria and can acquire $\mathrm{N}$ from them, SL production is promoted only under P deficiency, whereas non-leguminous mycotrophic plants such as sorghum may depend on AM symbionts for the supply of both $\mathrm{N}$ and $\mathrm{P}$.

In order to obtain deeper insight into the relationship between SL exudation and the nutrient acquisition strategy of plants, we examined the effects of $\mathrm{N}$ and $\mathrm{P}$ on plant growth, shoot $\mathrm{P}$ levels and SL exudation in members of the Fabaceae (Chinese milk vetch and alfalfa), Asteraceae (lettuce and marigold), Solanaceae (tomato), and Poaceae (wheat).

\section{Materials and methods}

\section{Chemicals}

Orobanchol was a generous gift of Emeritus Professor Kenji Mori (The University of Tokyo). 5-Deoxystrigol, $\left[6^{\prime}-{ }^{2} \mathrm{H}\right]$ orobanchol, and $\left[6^{\prime}-{ }^{2} \mathrm{H}\right]$ orobanchyl acetate were kindly provided by Dr. Kohki Akiyama (Osaka Prefecture University). $\left[3 \mathrm{a}, 4,4,5,5,6^{\prime}-{ }^{2} \mathrm{H}_{6}\right] 5$-Deoxystrigol was kindly provided by Professor Tadao Asami (The University of Tokyo). Orobanchyl acetate and sorgomol were purified from root exudates of red clover (Xie et al. 2008a) and sorghum (Xie et al. 2008b), respectively. The structures of orobanchol and orobanchyl acetate have been revised recently (Ueno et al. 2011). Although new names for these SLs have been proposed, we will use the names orobanchol and orobanchyl acetate as these have been used in numerous reports published to date. The other analytical grade chemicals and HPLC solvents were obtained from 
Kanto Chemical Co. Ltd. (Tokyo, Japan) and Wako Pure Chemical Industries Ltd. (Tokyo, Japan).

\section{Plants}

Seeds of Chinese milk vetch (Astragalus sinicus L. cv. Pinkyfield), alfalfa (Medicago sativa L. cv. BRS511), lettuce (Lactuca sativa L. cv. Chirimensha), marigold (Tagetes patula L. cv. Super), wheat (Triticum aestivum L. cv. Chinese Spring), and tomato (Solanum lycopersicum L. cv. Sekaiichi and Momotaro) were obtained from a local supplier. Tomato (S. lycopersicum L. cv. M82) seeds were generously supplied by Dr. Yaakov Goldwasser (Hebrew University of Jerusalem, Israel).

\section{Hydroponic culture}

Hydroponic culture was conducted as described previously (Yoneyama et al. 2007a, b). Plant seeds were surface-sterilized in 70\% ethanol for $2 \mathrm{~min}$ and then in $1 \% \mathrm{NaClO}$ for $5 \mathrm{~min}$. After thoroughly rinsing with sterile Milli-Q water, the seeds were germinated on moistened filter paper in Petri dishes for 2 days at $23^{\circ} \mathrm{C}$ (alfalfa, Chinese milk vetch, lettuce, marigold) or $28^{\circ} \mathrm{C}$ (tomato) in the dark. Wheat seeds were kept moist at $5^{\circ} \mathrm{C}$ for 2 days and then subjected to a temperature of $23^{\circ} \mathrm{C}$. Seedlings $(n=10)$ were transferred to a stainless steel sieve lined with a sheet of gauze moistened by placing it on a plastic cup $(9.5 \mathrm{~cm}$ in diameter, $17 \mathrm{~cm}$ deep, approximately $550 \mathrm{ml}$ in volume) containing $500 \mathrm{ml}$ tap water. The plants were grown in a growth chamber with a $14 / 10$-h photoperiod at $120 \mu \mathrm{mol}$ photons $\mathrm{m}^{-2} \mathrm{~s}^{-1}$ at $28^{\circ} \mathrm{C} /$ $25^{\circ} \mathrm{C}$ (tomato) or $23^{\circ} \mathrm{C} / 20^{\circ} \mathrm{C}$ (other plants). Half-strength Tadano and Tanaka (TT) medium (Tadano and Tanaka 1980) containing $2.43 \mathrm{mM} \mathrm{N}(1.43 \mathrm{mM} \mathrm{NaNO} 3,0.5 \mathrm{mM}$ $\left.\mathrm{NH}_{4} \mathrm{NO}_{3}\right), 0.16 \mathrm{mM} \quad \mathrm{NaH}_{2} \mathrm{PO}_{4} \cdot 2 \mathrm{H}_{2} \mathrm{O}, 0.5 \mathrm{mM} \quad \mathrm{K}_{2} \mathrm{SO}_{4}$, $1 \mathrm{mM} \mathrm{CaCl} 2 \cdot 2 \mathrm{H}_{2} \mathrm{O}$, and $1 \mathrm{mM} \mathrm{MgSO}{ }_{4} \cdot 7 \mathrm{H}_{2} \mathrm{O}$ was used as the basal culture medium with $1 \mathrm{mM}$ 4-morpholineethanesulfonic acid. The $\mathrm{pH}$ of all culture media was adjusted to 6.0 with $\mathrm{KOH}$. The seedlings were grown hydroponically with tap water for 5 days and in 1/2 TT medium for another 3 days. Plants were then subjected to each nutrient condition, with control plants subjected to $1 / 2$ TT media only. The respective $\mathrm{N}$-deficient and $\mathrm{P}$-deficient solutions were prepared by, respectively, removing each element from the $1 / 2$ TT media. After 10 days of acclimatization in the test media, the growth media containing root exudates (plus washings) were collected at 24-h intervals.

The effects of $\mathrm{P}$ and $\mathrm{N}$ concentrations in culture media on SL exudation and shoot $\mathrm{P}$ levels were examined in Chinese milk vetch. For $\mathrm{P}$ experiments, plants were preincubated under $-\mathrm{P}$ conditions for 10 days and then transferred to four different levels of $\mathrm{P} ; 8,20,80$, and $160 \mu \mathrm{M}$. For $\mathrm{N}$ experiments, N-deficient plants pre- incubated under $-\mathrm{N}$ conditions for 10 days and were subjected to different $\mathrm{N}$ levels: $0.12,0.6,1.2$, and $2.43 \mathrm{mM}$. After a 24-h incubation, culture media (plus washings) containing SLs were collected.

The effects of increased $\mathrm{P}$ concentration in culture media on SL exudation and shoot $\mathrm{P}$ levels were examined in Chinese milk vetch grown under $\mathrm{N}$ deficiency. The plants were grown under $\mathrm{N}$ deficiency ( $\mathrm{P}$ concentration; $160 \mu \mathrm{M})$ for 10 days and then transferred to 320 and $640 \mu \mathrm{M}$ P conditions or continuously grown in $160 \mu \mathrm{M}$ P. After a 24-h incubation, culture media (plus washings) containing SLs were collected.

\section{Extraction of SLs from root exudates}

Extraction of SLs from plant root exudates was conducted as described previously (Yoneyama et al. 2007a, b). The growth media containing root exudates (plus washings), approximately $450 \mathrm{ml}$ per cup, were extracted three times with an equal volume of ethyl acetate containing orobanchol- $\mathrm{d}_{1} \quad(200-2,000 \mathrm{pg})$, orobanchyl acetate- $\mathrm{d}_{1}$ $(50-2,000 \mathrm{pg})$, and 5-deoxystrigol-d 6 (50-500 pg) as internal standards. Amounts of the internal standards were adjusted to fall in the range of $1 / 10$ to tenfold that of endogenous levels of SLs. The ethyl acetate solutions were combined, washed with $0.2 \mathrm{M} \mathrm{K}_{2} \mathrm{HPO}_{4}(\mathrm{pH}$ 8.3), dried over anhydrous $\mathrm{MgSO}_{4}$, and concentrated in vacuo to afford root exudate samples. The samples were stored at $4^{\circ} \mathrm{C}$ until use.

\section{Quantification of SLs}

Quantification of SLs was conducted by high-performance liquid chromatography/tandem mass spectrometry (LCMS/MS) as described previously (Yoneyama et al. 2007a, b). HPLC separation was conducted using a U980 HPLC instrument (Jasco, Tokyo, Japan) fitted with an ODS $\left(\mathrm{C}_{18}\right)$ column (Mightysil RP-18, $2 \times 250 \mathrm{~mm}, 5 \mu \mathrm{m}$; Kanto Chemicals Co. Ltd, Tokyo, Japan). The mobile phase was $70 \%$ methanol in water (v/v) and was changed to $100 \%$ methanol $14 \mathrm{~min}$ after injection. The column was then washed with $100 \%$ methanol for 20 min to elute all the injected materials. The flow rate was $0.2 \mathrm{ml} \mathrm{min}^{-1}$, and the column temperature was set to $40^{\circ} \mathrm{C}$. Mass spectrometry was performed using a Quattro LC mass spectrometer (Micromass, Manchester, UK) equipped with an electrospray source. The gas used both for drying and nebulizing was nitrogen generated from pressurized air in an N2G nitrogen generator (Parker-Hanefin Japan, Tokyo, Japan). The nebulizer gas flow was set to approximately $100 \mathrm{l} \mathrm{h}^{-1}$, and the desolvation gas flow to $500 \mathrm{l} \mathrm{h}^{-1}$. The interface temperature was set to $400^{\circ} \mathrm{C}$, and the source temperature to $150^{\circ} \mathrm{C}$. The capillary and cone voltages were adjusted to orobanchol and to the positive ionization mode. MS/MS 
experiments were conducted using argon as the collision gas and the collision energy was set to $16 \mathrm{eV}$. The collision gas pressure was $0.15 \mathrm{~Pa}$. The transitions of $\mathrm{m} / \mathrm{z} 353$ to 256,359 to 262,367 to 270,365 to 268,369 to 272,370 to 273,411 to 254 , and 412 to 255 were monitored for 5-deoxystrigol, 5-deoxystrigol- $\mathrm{d}_{6}$, didehydro-orobanchol, solanacol, orobanchol (sorgomol), orobanchol- $\mathrm{d}_{1}$, orobanchyl acetate, and orobanchyl acetate- $\mathrm{d}_{1}$, respectively. Data acquisition and analysis were performed using MassLynx software (ver. 4.1). Quantification of sorgomol was conducted using natural standard in a manner similar to that described previously (Sato et al. 2003, 2005; Yoneyama et al. 2007a, b). Data presented were mean values of three experiments with ten plants each \pm standard deviation.

\section{$\mathrm{P}$ quantification in plant tissues}

$\mathrm{P}$ quantification of plant tissues was conducted as described previously (Yoneyama et al. 2007a, b). At the end of the experiments, plants were harvested and separated into shoots and roots. After oven-drying at $60^{\circ} \mathrm{C}$ for $72 \mathrm{~h}$, dry materials were ground by mill and decomposed by $13 \mathrm{~N}$ nitric acid. $\mathrm{P}$ concentrations were then determined by the vanado-molybdate yellow method (Nanamori et al. 2004).

Plant growth determination

After 10 days of acclimatization in the test media, plants were harvested and separated into shoots and roots. In wheat, the number of shoot and root branches could be determined. Since no apparent shoot branching was observed in the dicotyledonous plants grown under sufficient nutrient conditions, we determined in these plants the fresh weights and the number of leaves. In addition, we also examined the effect of nutrient deficiencies on the root system, but since the lateral roots were tangled, only primary root (PR) length was measured. Data presented show average values of ten plants.

\section{Statistical analysis}

Results were analyzed by analysis of variance (JMP 7, SAS Institute Inc., Cary, NC, USA) followed by Tukey's honest significance (HSD) test.

\section{Results}

Effects of $\mathrm{N}$ and $\mathrm{P}$ deficiencies on SL exudation in legumes and non-legumes

We have previously demonstrated that alfalfa cv. BRS511 exudes orobanchol and orobanchyl acetate, and Chinese milk vetch cv. Pinkyfield exudes sorgomol, orobanchyl acetate, and 5-deoxystrigol (Yoneyama et al. 2008). Lettuce cv. Chirimensha and marigold cv. Super were found to exude orobanchol and orobanchyl acetate (Yoneyama et al. 2011). In our preliminary studies, wheat cv. Chinese Spring was found to exude orobanchol (data not shown). One of the major SLs produced by tomato cv. M82 was orobanchol (Koltai et al. 2010). Therefore, amounts of these SLs (Fig. 1) exuded over $24 \mathrm{~h}$ were quantified by LC-MS/MS.

In tomato cv. M82, there were no changes in orobanchol exudation under $\mathrm{N}$ deficiency, but $\mathrm{P}$ deficiency significantly increased orobanchol exudation by about 100-fold compared with the controls (Fig. 2). Similar results were obtained for tomato cv. Sekaiichi and Momotaro (data not shown), which exude solanacol and didehydro-orobanchol(s) in addition to orobanchol. Since standards for these compounds, other than orobanchol, were not available, we have used the peak areas in LC-MS/MS chromatograms to estimate the relative quantities of both solanacol and didehydro-orobanchol(s). The areas of these SLs in root exudates from the plants grown under $-\mathrm{P}$ conditions were clearly larger than those of the controls, and $\mathrm{N}$ deficiency did not affect exudation of these SLs (data not shown). Therefore, tomato plants responded to $\mathrm{P}$ starvation by promoting exudation of orobanchol, solanacol, and didehydro-orobanchol(s) (López-Ráez et al. 2008).

On the tenth day of incubation under $-\mathrm{N}$ conditions, a strong growth inhibition was observed in tomato plants (Table 2). Therefore, in tomato, the growth inhibition due to $\mathrm{N}$ deficiency may give rise to reduced SL exudation. To investigate this possibility, the quantities of SLs were analyzed in root exudates of tomato plants grown under $\mathrm{N}$ deficiency for a short period, either 3 or 5 days. On the third day of the incubation, there were no obvious differences in growth among the plants grown under $-\mathrm{N}$ conditions, $-\mathrm{P}$ conditions, and the control conditions (data not shown). On the fifth day, symptoms of $\mathrm{N}$ starvation became visible, i.e., yellowing of leaves and suppressed growth. $\mathrm{P}$ deficiency also started to negatively affect plant growth on the fifth day (data not shown). Although distinct peaks of orobanchol, solanacol, and didehydro-orobanchol(s) could be observed in multiple reaction monitoring (MRM) chromatograms of root exudates collected from the tomato plants grown under $-\mathrm{P}$ conditions on the fifth and even on the third day of the incubation in the test media, these peaks could not be detected in the root exudates of tomato plants grown under control and $-\mathrm{N}$ conditions (data not shown). Therefore, in tomato, it is likely that only $\mathrm{P}$ deficiency, as reported previously (Lopéz-Ráez et al. 2008), but not $\mathrm{N}$ deficiency, influences SL exudation.

In Chinese milk vetch, exudation of sorgomol and 5-deoxystrigol was markedly promoted by $\mathrm{P}$ deficiency, by about 14,000- and 1,000-fold, respectively, compared with the 
Fig. 2 Effects of $-\mathrm{N}$ and $-\mathrm{P}$ on SL exudation in Chinese milk vetch cv. Pinkyfield, alfalfa cv. BRS511, lettuce cv.

Chirimensha, tomato cv. M82, wheat cv. Chinese Spring, and marigold cv. Super. Plants were grown hydroponically and root exudates were collected 10 days after subjection to each nutrient condition. White, gray, dark gray, and black bars indicate quantities of orobanchol, sorgomol, orobanchyl acetate, and 5-deoxystrigol $\left[\mathrm{pg} \mathrm{g}^{-1}\right.$ root fresh weight $(\mathrm{FW})]$,

respectively, exuded over $24 \mathrm{~h}$.

Values are mean \pm SD of three replicates. Different letters indicate statistically significant differences according to Tukey's test $(P<0.05)$

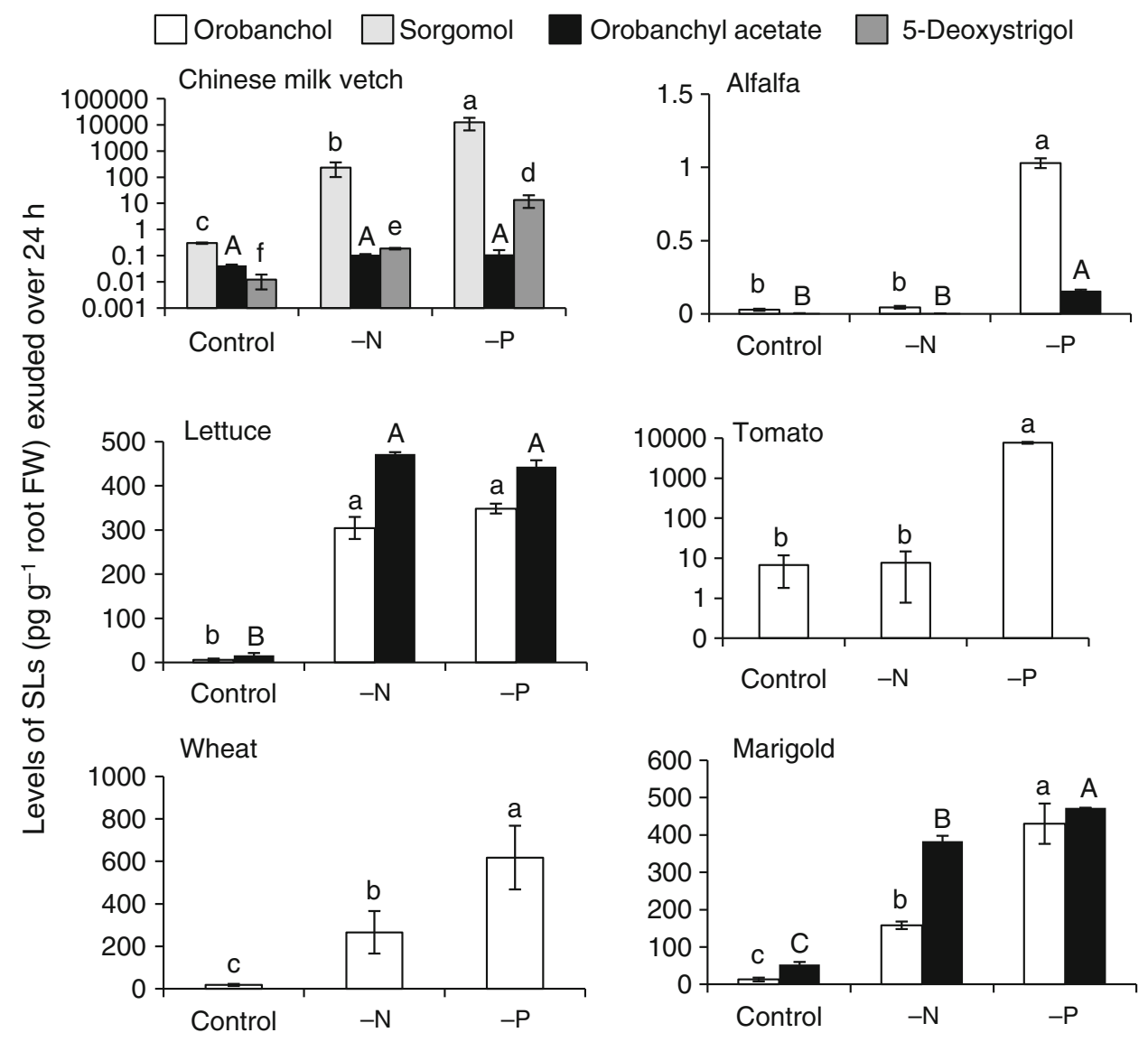

controls (Fig. 2). N deficiency also promoted SL exudation by about 1,000- and 20-fold, respectively. However, neither P nor $\mathrm{N}$ deficiency enhanced orobanchyl acetate exudation.

In alfalfa, only $\mathrm{P}$ deficiency promoted exudation of orobanchol and orobanchyl acetate, as in the case of red clover (Yoneyama et al. 2007a). In lettuce, wheat, and marigold, SL exudation was enhanced by both $\mathrm{N}$ deficiency and $\mathrm{P}$ deficiency, whereas in lettuce both $\mathrm{P}$ and $\mathrm{N}$ deficiencies increased the levels of SL exudation to a similar extent. In Chinese milk vetch, marigold, and wheat the levels of SL exudation from the plants grown under P deficiency were greater than those from the plants grown under $\mathrm{N}$ deficiency (Fig. 2).

Effects of $\mathrm{N}$ and $\mathrm{P}$ deficiency on plant growth

$\mathrm{N}$ and $\mathrm{P}$ deficiencies negatively and profoundly affected shoot growth; they decreased fresh weight and number of leaves (Tables 1, 2). However, at the same time, both nutrient deficiencies positively affected primary root (PR) elongation. In alfalfa, Chinese milk vetch, and marigold, there were no differences in PR length between the plants grown under $\mathrm{N}$ - and P-deficient conditions. In lettuce, $\mathrm{P}$ deficiency significantly promoted PR elongation, whereas $\mathrm{N}$ deficiency did only slightly. In tomato and wheat, $\mathrm{N}$ deficiency promoted PR elongation more significantly than did P deficiency.

Root fresh weight response to $\mathrm{N}$ and $\mathrm{P}$ deficiencies varied with plant species. The root fresh weight was increased by $\mathrm{N}$ deficiency in Chinese milk vetch, but was decreased in lettuce, marigold, and tomato. These nutrient deficiencies, however, did not affect root fresh weight in alfalfa and wheat.

In wheat, the number of shoot branches was decreased by $\mathrm{N}$ deficiency as well as by $\mathrm{P}$ deficiency, and $\mathrm{N}$ starvation reduced it more strongly (Table 2). The number of roots was also suppressed by both $\mathrm{N}$ and $\mathrm{P}$ deficiencies.

Effects of $\mathrm{N}$ and $\mathrm{P}$ deficiencies on $\mathrm{P}$ levels in plant tissues

$P$ starvation significantly decreased $P$ levels $\left[\mathrm{mg} \mathrm{g}^{-1}\right.$ dry weight (DW)] in the tissues of both shoots and roots of plants grown under conditions similar to those applied for SL analyses (Table 3). Interestingly, P shoot levels varied with plant species when they were grown hydroponically under $-\mathrm{N}$ conditions. In tomato plants, $\mathrm{N}$ starvation greatly increased P levels in both shoots and roots. In contrast, in the other plants such as Chinese milk vetch, $\mathrm{N}$ deficiency decreased shoot $\mathrm{P}$ level but increased root $\mathrm{P}$ level compared with the controls. 
Table 1 Effects of $-\mathrm{N}$ and $-\mathrm{P}$ conditions on plant growth

\begin{tabular}{|c|c|c|c|c|c|}
\hline & & \multicolumn{2}{|l|}{ FW (mg) } & \multirow[t]{2}{*}{ Number of leaves } & \multirow[t]{2}{*}{ Length $(\mathrm{cm})$ of PR } \\
\hline & & Shoot & Root & & \\
\hline \multirow{3}{*}{$\begin{array}{l}\text { Chinese } \\
\text { milk vetch }\end{array}$} & Control & $128.7 \pm 13.1 \mathrm{a}$ & $78.9 \pm 6.3 b$ & $4.6 \pm 0.5 \mathrm{a}$ & $10.1 \pm 0.6 \mathrm{~b}$ \\
\hline & $-\mathrm{N}$ & $81.8 \pm 15.3 \mathrm{~b}$ & $113.2 \pm 16.4 \mathrm{a}$ & $3.0 \pm 0.0 \mathrm{~b}$ & $14.5 \pm 2.4 \mathrm{a}$ \\
\hline & $-\mathrm{P}$ & $87.8 \pm 17.2 \mathrm{~b}$ & $108.9 \pm 17.2 \mathrm{a}$ & $3.6 \pm 0.5 b$ & $15.1 \pm 0.4 \mathrm{a}$ \\
\hline \multirow[t]{3}{*}{ Alfalfa } & Control & $217.7 \pm 31.2 \mathrm{a}$ & $86.2 \pm 9.8 \mathrm{a}$ & $5.0 \pm 0.0 \mathrm{a}$ & $19.6 \pm 3.1 \mathrm{~b}$ \\
\hline & $-\mathrm{N}$ & $59.6 \pm 15.4 \mathrm{c}$ & $73.5 \pm 13.1 \mathrm{a}$ & $2.4 \pm 0.5 \mathrm{c}$ & $31.9 \pm 2.8 \mathrm{a}$ \\
\hline & $-\mathrm{P}$ & $124.8 \pm 40.2 \mathrm{~b}$ & $97.2 \pm 21.2 \mathrm{a}$ & $3.6 \pm 0.5 \mathrm{~b}$ & $27.2 \pm 2.8 \mathrm{a}$ \\
\hline \multirow[t]{3}{*}{ Lettuce } & Control & $324.4 \pm 33.9 \mathrm{a}$ & $80.5 \pm 5.7 \mathrm{a}$ & $4.6 \pm 0.5 \mathrm{a}$ & $12.1 \pm 0.7 \mathrm{~b}$ \\
\hline & $-\mathrm{N}$ & $106.4 \pm 14.4 \mathrm{c}$ & $38.6 \pm 1.2 \mathrm{c}$ & $2 \pm 0 \mathrm{c}$ & $13.1 \pm 0.9 \mathrm{ab}$ \\
\hline & $-\mathrm{P}$ & $194.7 \pm 27.9 \mathrm{~b}$ & $61.2 \pm 11.0 \mathrm{~b}$ & $3 \pm 0 \mathrm{~b}$ & $13.7 \pm 1.0 \mathrm{a}$ \\
\hline \multirow[t]{3}{*}{ Tomato } & Control & $817.8 \pm 92.9 \mathrm{a}$ & $286.3 \pm 62.9 \mathrm{a}$ & $3.2 \pm 0.4 \mathrm{a}$ & $18.0 \pm 1.5 \mathrm{c}$ \\
\hline & $-\mathrm{N}$ & $156.8 \pm 24.8 \mathrm{c}$ & $80.4 \pm 18.7 \mathrm{c}$ & $2.0 \pm 0 \mathrm{~b}$ & $39.5 \pm 5.2 \mathrm{a}$ \\
\hline & $-\mathrm{P}$ & $328.5 \pm 27.4 \mathrm{~b}$ & $200.6 \pm 39.6 \mathrm{~b}$ & $2.6 \pm 0.5 \mathrm{ab}$ & $26.0 \pm 1.0 \mathrm{~b}$ \\
\hline \multirow[t]{3}{*}{ Marigold } & Control & $982.2 \pm 123.1 \mathrm{a}$ & $721.0 \pm 98.5 \mathrm{a}$ & $5.4 \pm 0.5 \mathrm{a}$ & $25.7 \pm 2.2 \mathrm{~b}$ \\
\hline & $-\mathrm{N}$ & $115.3 \pm 14.9 \mathrm{c}$ & $146.3 \pm 16.7 \mathrm{c}$ & $2 \pm 0 \mathrm{c}$ & $38.4 \pm 0.9 \mathrm{a}$ \\
\hline & $-\mathrm{P}$ & $254.3 \pm 44.4 \mathrm{~b}$ & $313.2 \pm 42.2 \mathrm{~b}$ & $3.6 \pm 0.5 \mathrm{~b}$ & $37.9 \pm 0.9 \mathrm{a}$ \\
\hline
\end{tabular}

Plants were harvested 10 days after subjection to each nutrient condition. Values are the mean $\pm \mathrm{SD}(n=16)$. Different letters indicate significant differences $(P<0.05)$ calculated by Tukey's multiple test

Table 2 Effects of $-\mathrm{N}$ and $-\mathrm{P}$ conditions on plant growth in wheat

\begin{tabular}{|c|c|c|c|c|c|}
\hline & \multicolumn{2}{|l|}{ FW (mg) } & \multirow{2}{*}{$\begin{array}{l}\text { Number of shoot } \\
\text { branches }\end{array}$} & \multirow{2}{*}{$\begin{array}{l}\text { Length }(\mathrm{cm}) \\
\text { of PR }\end{array}$} & \multirow[t]{2}{*}{ Number of roots } \\
\hline & Shoot & Root & & & \\
\hline Control & $1174.3 \pm 104.6 \mathrm{a}$ & $1088.6 \pm 206.6 \mathrm{a}$ & $3.0 \pm 0.0 \mathrm{a}$ & $18.9 \pm 1.1 \mathrm{c}$ & $14.8 \pm 1.0 \mathrm{a}$ \\
\hline$-\mathrm{N}$ & $567.6 \pm 18.5 \mathrm{c}$ & $776.5 \pm 47.3 \mathrm{a}$ & $1.0 \pm 0.0 \mathrm{c}$ & $28.0 \pm 0.7 \mathrm{a}$ & $11.2 \pm 1.3 \mathrm{~b}$ \\
\hline$-\mathrm{P}$ & $807.1 \pm 100.4 \mathrm{~b}$ & $818.8 \pm 141.5 \mathrm{a}$ & $2.0 \pm 0.0 \mathrm{~b}$ & $22.2 \pm 2.3 \mathrm{~b}$ & $12.4 \pm 0.9 \mathrm{~b}$ \\
\hline
\end{tabular}

Plants were harvested 10 days after subjection to each nutrient condition. Values are the mean \pm SD $(n=6)$. Different letters indicate significant differences $(P<0.05)$ calculated by Tukey's multiple test

Table 3 P levels (mg/g FW) in shoot and root tissues

\begin{tabular}{|c|c|c|c|c|c|c|}
\hline & \multicolumn{2}{|l|}{ Control } & \multicolumn{2}{|l|}{$-\mathrm{N}$} & \multicolumn{2}{|l|}{$-\mathrm{P}$} \\
\hline & Shoot & Root & Shoot & Root & Shoot & Root \\
\hline \multicolumn{7}{|l|}{ Asteraceae } \\
\hline Lettuce & $12.7 \pm 0.5$ & $9.8 \pm 0.5$ & $9.4 \pm 0.5$ & $10.6 \pm 0.3$ & $4.1 \pm 0.1$ & $3.0 \pm 0.3$ \\
\hline Marigold & $8.0 \pm 0.4$ & $8.8 \pm 0.5$ & $6.9 \pm 0.2$ & $10.0 \pm 0.2$ & $3.4 \pm 0.02$ & $4.6 \pm 0.1$ \\
\hline \multicolumn{7}{|l|}{ Fabaceae } \\
\hline Chinese milk vetch & $8.4 \pm 0.5$ & $12.8 \pm 0.7$ & $6.6 \pm 0.5$ & $18.2 \pm 0.4$ & $4.1 \pm 0.1$ & $4.4 \pm 0.2$ \\
\hline Alfalfa & $5.0 \pm 0.6$ & $7.6 \pm 0.4$ & $4.2 \pm 0.01$ & $10.0 \pm 0.2$ & $2.2 \pm 0.2$ & $2.7 \pm 0.2$ \\
\hline \multicolumn{7}{|l|}{ Poaceae } \\
\hline Wheat & $5.5 \pm 0.4$ & $5.1 \pm 0.5$ & $3.7 \pm 0.5$ & $2.9 \pm 0.7$ & $1.2 \pm 0.1$ & $2.1 \pm 0.3$ \\
\hline \multicolumn{7}{|l|}{ Solanaceae } \\
\hline Tomato & $4.3 \pm 0.6$ & $6.4 \pm 0.4$ & $12.5 \pm 0.2$ & $12.0 \pm 0.3$ & $1.0 \pm 0.2$ & $1.6 \pm 0.1$ \\
\hline
\end{tabular}

Shoot and root tissues of plants subjected to each nutrient condition were collected 10 days after nutrient treatments. Results are means \pm SD $(n=3)$ 
Fig. 3 Quantities of sorgomol (gray bars), 5-deoxystrigol (dark gray bars), and orobanchyl acetate (black bars) exuded over $24 \mathrm{~h} \mathrm{(a)}$ and shoot $\mathrm{P}$ levels (b) of Chinese milk vetch plants grown in media containing different concentrations of $\mathrm{P}(\mathbf{a}, \mathbf{b})$ and $\mathrm{N}$ (c, d). Values are mean $\pm \mathrm{SD}$ of three replicates. Different letters indicate statistically significant differences according to Tukey's test $(P<0.05)$
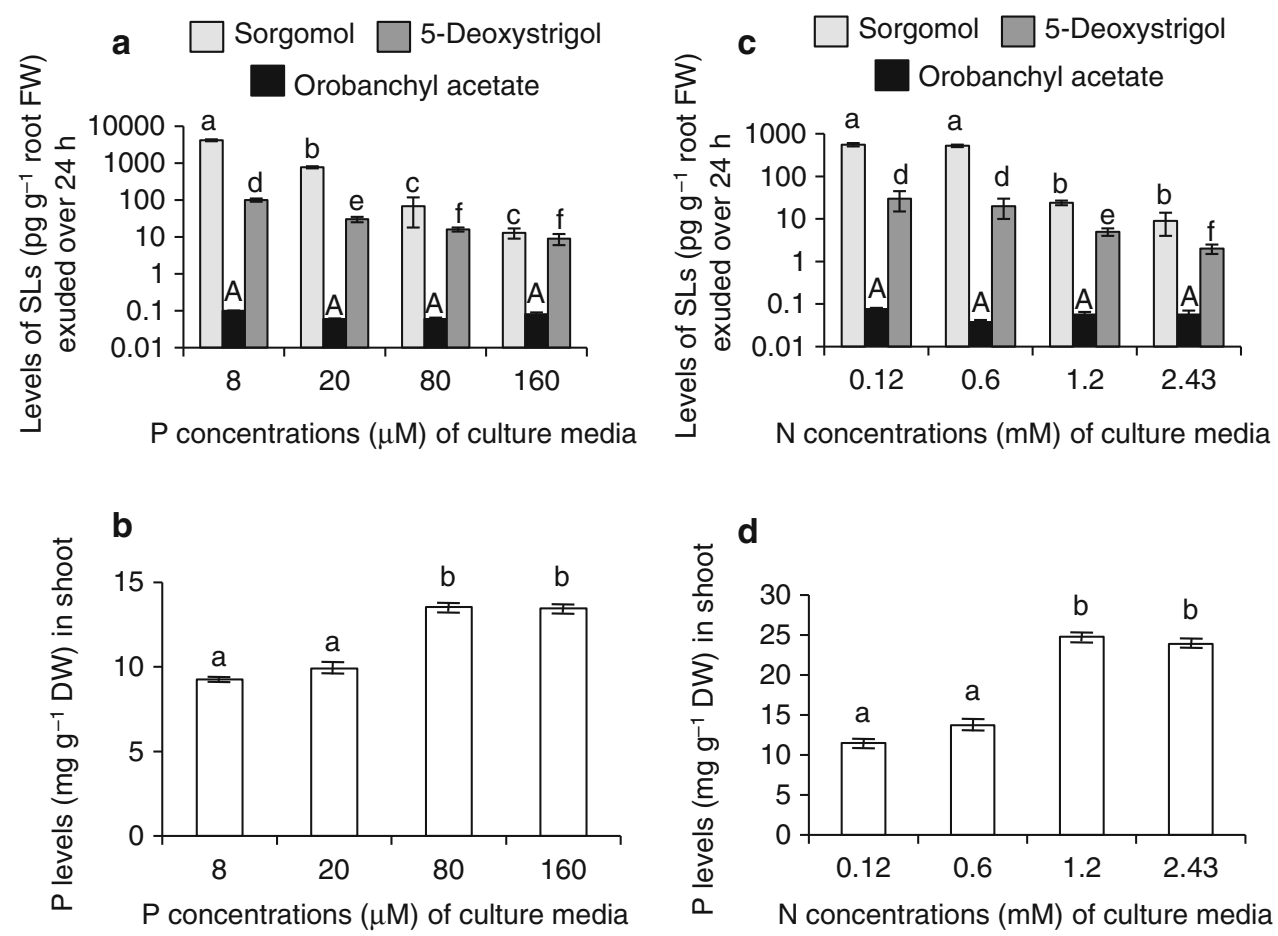



Orobanchyl acetate exudation by Chinese milk vetch was not affected by nutrient conditions (Fig. 3a). However, with the increase in $\mathrm{P}$ concentration in the culture media, the exudation of both sorgomol and 5-deoxystrigol decreased (Fig. 3a) and shoot P levels increased (Fig. 3b). Similar trends in SL exudation and shoot $\mathrm{P}$ levels were also observed under increased $\mathrm{N}$ concentration (Fig. 3c, d).

SL exudation was not suppressed by $\mathrm{P}$ supplementation in plants grown under $\mathrm{N}$ deficiency (Fig. 4a), and no increase in shoot $\mathrm{P}$ level was observed (Fig. 4b). Similar results were obtained with marigold, lettuce, and wheat, where $\mathrm{P}$ supplementation influenced neither SL exudation nor shoot $\mathrm{P}$ levels (data not shown).

\section{Discussion}

Our research was aimed to clarify whether a plant's ability to form symbiotic relationships with root nodule bacteria determines the response of SL exudation to nutrient availability. For this purpose, we examined the effects of $\mathrm{N}$ and $\mathrm{P}$ deficiency on SL exudation not only in two legumes but also, for proper comparison, in four non-legume plant species of different families.

According to the response of SL exudation to $\mathrm{N}$ availability, the plant species examined in this study can be classified into two groups. Whereas all plants examined exuded higher levels of SLs under $\mathrm{P}$ deficiency, $\mathrm{N}$ deficiency in both alfalfa and tomato did not enhance SL
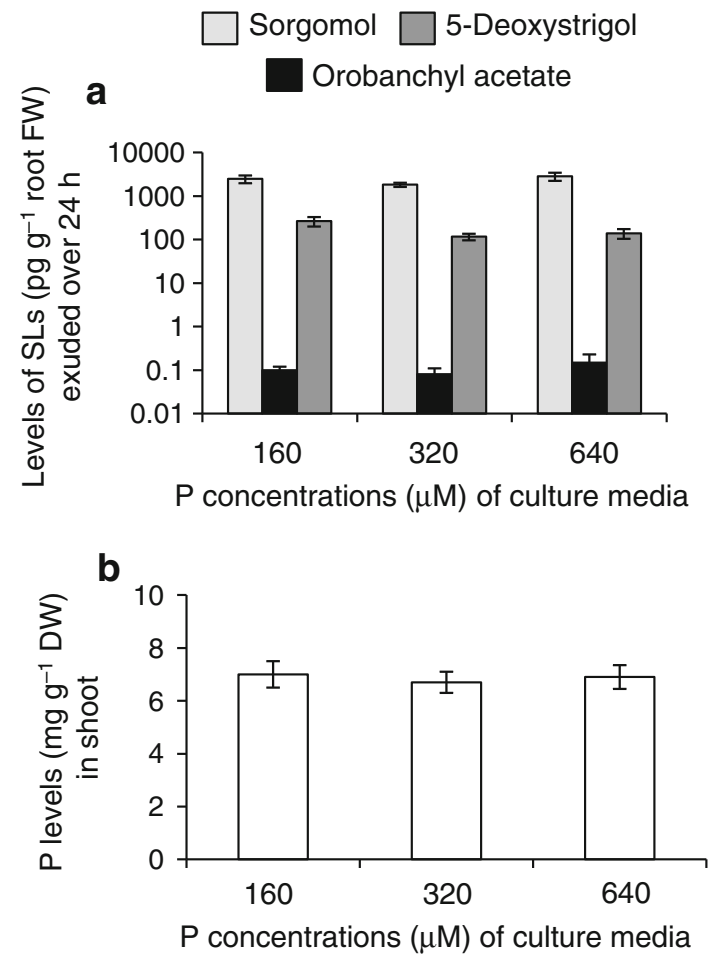

Fig. 4 Quantities of sorgomol (gray bars), 5-deoxystrigol (dark gray bars), and orobanchyl acetate (black bars) exuded over $24 \mathrm{~h}$ (a) and shoot $\mathrm{P}$ levels (b) of Chinese milk vetch plants grown in media containing different concentrations of $\mathrm{P}$ under $-\mathrm{N}$ conditions. Values are mean $\pm \mathrm{SD}$ of three replicates. Different letters indicate statistically significant differences according to Tukey's test $(P<0.05)$ 
exudation. In contrast, in the other plant species, $\mathrm{N}$ as well as P deficiency enhanced SL exudation (Fig. 2). Interestingly, this latter group includes the Chinese milk vetch, which is a legume, while the former group, which does not respond to $\mathrm{N}$ deficiency, includes the tomato, which is a non-legume plant. Since N deficiency did not promote SL exudation in tomato, whereas it did in the leguminous Chinese milk vetch, plant response of SL exudation to nutrient availability does not seem to be directly related to the plant's ability to form symbiotic relationships with root nodule bacteria.

Does the tomato plant have an alternative strategy for obtaining $\mathrm{N}$, other than from symbiotic relationships with AM fungi under $\mathrm{N}$ starvation? It has already been established that, in addition to the importance of nodulation for plant nutrition, beneficial plant-bacteria interactions for $\mathrm{N}$ nutrition are also observed within plant species that do not form root nodules (Kraiser et al. 2011). Interactions between non-nodulating plants and $\mathrm{N}$-fixing bacteria are functional associations that have received considerably less attention than the plant-bacteria interactions leading to nodule formation (Kraiser et al. 2011). N-fixing bacteria can colonize the rhizosphere of the plant and may also colonize plant tissues and exhibit an endophytic lifestyle. For example, isotope studies showed that sugarcane and wetland rice obtained significant quantities of $\mathrm{N}$ through $\mathrm{N}$ fixing bacteria (Boddey et al. 1995). In wheat plants inoculated with Klebsiella pneumoniae 342, N deficiency symptoms were relieved and total $\mathrm{N}$ concentration in the plants increased (Iniguez et al. 2004). Therefore, the lack of an increase in SL exudation from tomato roots under $\mathrm{N}$ deficiency may indicate that these plants are capable of obtaining $\mathrm{N}$ from such symbiotic bacteria. Indeed, the $\mathrm{N}$-fixing bacterium Burkholderia sp. was isolated from roots of tomato plants grown in the field (CaballeroMellado et al. 2007). Therefore, we hypothesize that tomato plants may attract $\mathrm{N}$-fixing bacteria rather than $\mathrm{AM}$ fungi under $\mathrm{N}$ deficiency and so do not need to increase SL production under these conditions. Among the other plant species that do respond to low $\mathrm{N}$ with enhanced SL production, wheat has been shown to obtain a significant portion of its $\mathrm{N}$ requirement from $\mathrm{N}$-fixing bacteria (Iniguez et al. 2004; Rosenblueth and Martínez-Romero 2006). In lettuce and marigold, endophytic bacteria may also enhance nutrient acquisition, for example, by solublizing inorganic and organic phosphate (Cocking 2003; Rosenblueth and Martínez-Romero 2006).

As in the case of red clover (Yoneyama et al. 2008a), other legumes including alfalfa (Fig. 2), crimson clover (Trifolium incarnatum cv. Strawberry-torch, data not shown), and adzuki bean (Vigna angularis cv. Dainagon, data not shown) did not promote SL exudation under $\mathrm{N}$ deficiency. Therefore, Chinese milk vetch may be an exceptional legume, which responds to $\mathrm{N}$ deficiency by enhancing SL exudation. The exceptional behavior of Chinese milk vetch is also puzzling. Does it mean that this leguminous plant is not dependant on $\mathrm{N}$ supply from nodulating N fixing bacteria? Exogenously applied GR24, a synthetic SL, promoted nodulation in alfalfa but did not affect the expression of nod genes in alfalfa Rhizobium (Soto et al. 2010). It is well known that plant-root nodule bacteria have strict host specificity and, therefore, SLs or special blends of SLs may possibly cause a Rhizobium specific for Chinese milk vetch to commence symbiosis. Alternatively, Chinese milk vetch plants may depend on AM fungi for the supply of $\mathrm{N}$ until they form root nodules. Environmental stress negatively affects symbiotic relationships with both root nodule bacteria and AM fungi. However, it was reported that, in copper polluted soil, inoculating with AM fungi improved Chinese milk vetch growth by increasing the uptake of not only $\mathrm{P}$ but also $\mathrm{N}$ (Chen and Zhao 2005). Thus, Chinese milk vetch may have a flexible ability to form relationships with nodulating $\mathrm{N}$-fixing bacteria or $\mathrm{AM}$ fungi for $\mathrm{N}$ acquisition under various environmental conditions. Further study is needed to clarify the reason why other legumes would not benefit from this and hence use the same mechanism.

In this study, a clear relationship between $\mathrm{P}$ contents in shoot tissues and SL exudation of plants grown under $\mathrm{N}$ deficiency was unveiled. In all the plants examined except for tomato, $\mathrm{N}$ deficiency decreased $\mathrm{P}$ levels in shoots, which resulted in increased SL exudation. Indeed, $\mathrm{N}$ concentrations of culture media were found to affect both levels of SL exudation and shoot P levels in Chinese milk vetch (Fig. 3). When shoot $\mathrm{P}$ levels were low, SL exudation was promoted, and when shoot $\mathrm{P}$ levels were high, SL exudation was suppressed in this plant when grown under $\mathrm{N}$ deficiency. The shoot $\mathrm{P}$ levels of the plants grown in the culture media with 0.12 and $0.6 \mathrm{mM} \mathrm{N}$ were approximately $10 \mathrm{mg} \mathrm{g}^{-1} \mathrm{DW}$ (Fig. 3d), which corresponds to those of the plants subjected to $20 \mu \mathrm{M} \mathrm{P}$ (Fig. 3b) and levels of SL exudation were very similar between these plants (Fig. 3a, c). These results suggest that, at least in Chinese milk vetch, decreased $\mathrm{P}$ levels in shoots may induce SL exudation and that the $\mathrm{P}$ status in the shoot would regulate SL production and exudation from the roots. Moreover, $\mathrm{P}$ supplementation to the culture media influenced neither shoot $\mathrm{P}$ levels nor SL exudation in Chinese milk vetch plants grown under $\mathrm{N}$ deficiency (Fig. 4), suggesting that $\mathrm{N}$ deficiency may regulate $\mathrm{P}$ metabolism and/or $\mathrm{P}$ transport from roots to shoots (Table 3).

Little is known about $\mathrm{P}$ sensing and signaling in plants (Franco-Zorrilla et al. 2004; Schachtman and Shin 2007; Chiou and Lin 2011). Early signals in response to $P$ deprivation may occur when external concentrations of $\mathrm{P}$ 
are reduced, and the later signals may be initiated when internal stores of $\mathrm{P}$ are reduced below a critical level (Chiou and Lin 2011). Since P heterogeneously exists in soils, the internal $\mathrm{P}$ level is considered the regulator for $\mathrm{P}$ homeostasis. Mutant and split root experiments suggested that shoot $\mathrm{P}$ status controls $\mathrm{P}$-starvation responses in the root (Franco-Zorrilla et al. 2004). From experiments using the Arabidopsis pho2 mutant, which over-accumulates $\mathrm{P}$ in shoots, the shoot $\mathrm{P}$ status was found to influence the root system architecture response to $\mathrm{P}$ availability (Williamson et al. 2001). In Medicago truncatula and tomato, when roots of P-starved plants were divided and one part was exposed to a high $\mathrm{P}$ medium while the other was left in a low-P medium, P-starvation responses were systemically repressed in the parts of the roots exposed to low-P medium (Liu et al. 1998; Burleigh and Harrison 1999). P did not accumulate in the unfertilized half of the split roots, despite the accumulation of $\mathrm{P}$ in the shoot (Burleigh and Harrison 1999). Similar P movement phenomena were observed in the split root petunia (Petunia hybrida), in which the expression of genes encoding enzymes involved in SL biosynthesis was repressed under high-P conditions (Breuillin et al. 2010). In fact, our results in split root sorghum of plants grown under $\mathrm{N}$ and $\mathrm{P}$ deficiency demonstrated that $\mathrm{N}$ and $\mathrm{P}$ fertilization systemically suppresses SL exudation and $\mathrm{N}$ and $\mathrm{P}$ accumulate in the shoot and not in the unfertilized half of the split roots. A negative correlation between shoot $\mathrm{P}$ levels and SL exudation was observed under these conditions (unpublished data). Similar systemic effects of P on SL exudation in split root pea have been reported (Balzergue et al. 2011); however, in this study, only peak areas of SLs in LC-MS chromatograms were compared.

Clear differences in the number of shoot branches were observed only in wheat plants grown under different nutrient conditions (Table 2), and not in the legumes and other dicotyledonous plants examined. Umehara et al. (2010) demonstrated a negative correlation in rice plants between SL concentration in root exudates and the number of outgrowing tillers. In this case, the SL levels in root exudates gradually decreased and the number of outgrowing tillers increased in response to increasing concentrations of P in the media (Umehara et al. 2010). However, such a correlation was not seen in wheat plants where SL exudation and the number of shoot branches were evidently smaller in the plants grown under $\mathrm{N}$ deficiency than those grown under $\mathrm{P}$ deficiency (Fig. 2; Table 1). These results suggest that in $\mathrm{N}$ starvation, not only SL but also other factors including $\mathrm{N}$ deficiency itself strongly regulate shoot branching.

It has been reported that $\mathrm{N}$ and $\mathrm{P}$ starvation reduce $\mathrm{PR}$ growth and enhance lateral root development and consequently promote $\mathrm{N}$ and $\mathrm{P}$ acquisition (Williamson et al.
2001; Linkohr et al. 2002). However, in all the plants examined in this study PR elongation was enhanced under $\mathrm{N}$ and $\mathrm{P}$ starvation (Tables 1,2). These conflicting results may be caused by different culture methods for the plants, different periods of $\mathrm{N}$ and $\mathrm{P}$ starvation, and plant species.

In addition to SLs' role in inhibiting shoot branching (Gomez-Roldan et al. 2008; Umehara et al. 2008), a new role for SLs was discovered in the regulation of root development (Koltai 2011). Ruyter-Spira et al. (2011) demonstrated that PR lengths of SL-deficient Arabidopsis plants were shorter than those of wild-type plants and GR24 application rescued their phenotype. In tomato and alfalfa, $\mathrm{N}$ deficiency did not enhance SL production in roots but promoted PR elongation. These results indicate that at least in alfalfa and tomato under $\mathrm{N}$ deficiency, other factors than SLs may promote PR elongation.

Chinese milk vetch was found to exude at least three SLs including sorgomol, orobanchyl acetate, and 5-deoxystirigol (Yoneyama et al. 2008). Exudation of sorgomol and 5-deoxystrigol was promoted by $\mathrm{N}$ and $\mathrm{P}$ deficiency, but orobanchyl acetate exudation was not. These results support the hypothesis that plants produce all SLs, but increase exudation only of particular SLs. In addition, it should be noted that sorgomol was derived from 5-deoxystrigol, while orobanchyl acetate (orobanchol) was from ent-2'-epi-5-deoxystrigol. These two different biosynthetic pathways for SLs starting from either 5-deoxystrigol or ent-2'-epi-5-deoxystrigol seem to be regulated somewhat independently under $\mathrm{N}$ and $\mathrm{P}$ deficiency. In Chinese milk vetch, the former pathway appears to be more sensitive than the latter to $\mathrm{N}$ and $\mathrm{P}$ deficiency.

Structural requirements of SLs for hyphal branching in AM fungi and germination stimulation of root parasite seeds have been reported. Among 20 natural and chemically modified natural SLs, 5-deoxystrigol and orobanchol gave rise to a strong hyphal branching activity on the AM fungus Gigaspora margarita (Akiyama et al. 2010). In the case of germination stimulation activity in $O$. minor, orobanchol showed a highly potent activity (Kim et al. 2010). To utilize AM symbiosis for agricultural production and at the same time to mitigate damage caused by root parasitic weeds, it is necessary to clarify which SLs that are exuded by a plant are involved in each interaction. Furthermore, the inhibition of shoot branching is one of key regulatory systems involved in completing plants' life cycles under nutrient limited conditions and severe environments. Therefore, an understanding of the regulation mechanisms for the production and exudation of the various SLs is essential for optimizing the utilization of SLs in agricultural and natural eco-systems.

Acknowledgments We acknowledge Emeritus Prof. Kenji Mori (The University of Tokyo, Japan), Prof. Tadao Asami (The University 
of Tokyo, Japan), and Dr. Kohki Akiyama (Osaka Prefecture University, Japan) for the generous gifts of synthetic standards and deuterium labeled internal standards. We also acknowledge Dr. Tatsuhiro Ezawa (Hokkaido University, Japan) for his critical comments and fruitful discussions. We thank Dr. Yaakov Goldwasser for supplying tomato seeds. We are grateful to Dr. D. M. Joel (ARO, Israel) for advices, discussions, and critical reading of the manuscript. Part of this work was supported by KAKENHI (18208010, 2109111, 23380061) from the Japan Society for the Promotion of Science (JSPS) and by the Program for the Promotion of Basic and Applied Researches for Innovations in Biooriented Industry. Kaori Yoneyama was supported by a JSPS Research Fellowship for Young Scientists.

Conflict of interest The authors declare that they have no conflict of interest.

Open Access This article is distributed under the terms of the Creative Commons Attribution Noncommercial License which permits any noncommercial use, distribution, and reproduction in any medium, provided the original author(s) and source are credited.

\section{References}

Akiyama K, Matsuzaki K, Hayashi H (2005) Plant sesquiterpenes induce hyphal branching in arbuscular mycorrhizal fungi. Nature 435:824-827

Akiyama K, Ogasawara S, Ito S, Hayashi H (2010) Structural requirements of strigolactones for hyphal branching in AM fungi. Plant Cell Physiol 51:1104-1117

Ames RN, Reid CPP, Porter LK, Cambardella C (1983) Hyphal uptake and transport of nitrogen from two ${ }^{15} \mathrm{~N}$ labelled sources by Glomus mosseae, a vesicular-arbuscular mycorrhizal fungus. New Phytol 95:381-396

Balzergue C, Puech-Pagès V, Bécard G, Rochange SF (2011) The regulation of arbuscular mycorrhizal symbiosis by phosphate in pea involves early and systemic signalling events. J Exp Bot 62:1049-1060

Besserer A, Puech-Pagès V, Kiefer P, Gomez-Roldan V, Jauneau A, Roy S, Portais J-C, Roux C, Bécard G, Séjalon-Delmas N (2006) Strigolactones stimulate arbuscular mycorrhizal fungi by activating mitochondria. PLoS Biol 4:1239-1247

Boddey RM, de Oliveira OC, Urquiaga S, Reis VM, de Olivares FL, Baldani VLD, Döbereiner J (1995) Biological nitrogen fixation associated with sugar cane and rice: contributions and prospects for improvement. Plant Soil 174:195-209

Breuillin F, Schramm J, Hajirezaei M, Ahkami A, Favre P, Druege U, Hause B, Bucher M, Kretzschmar T, Bossolini E, Kuhlemeier C, Martinoia E, Franken P, Scholz U, Reinhardt D (2010) Phosphate systemically inhibits development of arbuscular mycorrhiza in Petunia hybrida and represses genes involved in mycorrhizal functioning. Plant J 64:1002-1017

Burleigh SH, Harrison MJ (1999) The down regulation of Mt4 like genes by phosphate fertilization occurs systemically and involves phosphate translocation to the shoots. Plant Physiol 119:241-248

Caballero-Mellado J, Onofre-Lemus J, Estrada-de los Santos P, Martínez-Aguilar L (2007) The tomato rhizosphere, an environment rich in nitrogen-fixing Burkholderia species with capabilities of interest for agriculture and bioremediation. Appl Environ Microbiol 73:5308-5319

Chen X-H, Zhao B (2005) Effect of arbuscular mycorrhizal fungi on uptake of N, P and K by Astragalus sinicus L. in copper polluted soil. J Agro Environ Sci 24:441-478
Chiou T-J, Lin S-I (2011) Signaling network in sensing phosphate availability in plants. Annu Rev Plant Biol 62:185-206

Cocking EC (2003) Endophytic colonization of plant roots by nitrogen-fixing bacteria. Plant Soil 252:169-175

Epstein E, Bloom AJ (2005) Mineral nutrition of plants: principles and perspectives, 2nd edn. Sinauer Associates, Massachusetts

Franco-Zorrilla JM, González E, Bustos R, Linhares F, Leyva A, PazAres J (2004) The transcriptional control of plant responses to phosphate limitation. J Exp Bot 55:285-293

Gomez-Roldan V, Fermas S, Brewer PB, Puech-Pagès V, Dun EA, Pillot J-P, Letisse F, Matusova R, Danoun S, Portais J-C, Bouwmeester $\mathrm{H}$, Bécard G, Beveridge CA, Rameau C, Rochange SF (2008) Strigolactone inhibition of shoot branching. Nature 455:189-194

Govindarajulu M, Pfeffer PE, Jin H, Abubaker J, Douds DD, Allen JW, Bücking H, Lammers PJ, Shachar-Hill Y (2005) Nitrogen transfer in the arbuscular mycorrhizal symbiosis. Nature 435: 819-823

Iniguez AL, Dong Y, Triplett EW (2004) Nitrogen fixation in wheat provided by Klebsiella pneumoniae 342. Mol Plant Microbe Interact 17:1078-1085

Jamil M, Charnikhova T, Cardoso C, Jamil T, Ueno K, Verstappen F, Asami T, Bouwmeester HJ (2011) Quantification of the relationship between strigolactones and Striga hermonthica infection in rice under varying levels of nitrogen and phosphorus. Weed Res 51:373-385

Jin H, Pfeffer PE, Douds DD, Piotrowski E, Lammers PJ, ShacharHill Y (2005) The uptake, metabolism, transport and transfer of nitrogen in an arbuscular mycorrhizal symbiosis. New Phytol 168:687-696

Johansen A, Finlay RD, Olsson PA (1996) Nitrogen metabolism of the external hyphae of the arbuscular mycorrhizal fungus Glomus intraradices. New Phytol 133:705-712

Kim HI, Xie X, Kim HS, Chun JC, Yoneyama K, Nomura T, Takeuchi Y, Yoneyama K (2010) Structure-activity relationship of naturally occurring strigolactones in Orobanche minor seed germination stimulation. J Pestic Sci 35:344-347

Koltai H (2011) Strigolactones are regulators of root development. New Phytol 190:545-549

Koltai H, LekKala SP, Bhattacharya C, Mayzlish-Gati E, REsnick N, Wininger S, Dor E, Yoneyama K, Yoneyama K, Hershenhorn J, Joel DM, Kapulnik Y (2010) A tomato strigolactone-impaired mutant displays aberrant shoot morphology and plant interactions. J Exp Bot 61:1739-1749

Kraiser T, Gras DE, Gutiérrez AG, González B, Gutiérrez RA (2011) A holistic view of nitrogen acquisition in plants. J Exp Bot 62:1455-1466

Linkohr IB, Williamson LC, Fitter AH, Leyser HMO (2002) Nitrate and phosphate availability and distribution have different effects on root system architecture of Arabidopsis. Plant J 29:751-760

Liu C, Muchhal US, Uthappa M, Kononowicz KK, Raghothama KG (1998) Tomato phosphate transporter genes are differentially regulated in plant tissues by phosphorus. Plant Physiol 116:91-99

López-Ráez JA, Charnikhova T, Gómez-Roldán V, Matusova R, Kohlen W, De Vos R, Verstappen F, Puech-Pages V, Bécard G, Mulder P, Bouwmeester H (2008) Tomato strigolactones are derived from carotenoids and their biosynthesis is promoted by phosphate starvation. New Phytol 178:863-874

Nanamori M, Shinano T, Wasaki J, Yamamura T, Rao IM, Osaki M (2004) Low phosphorus tolerance mechanisms: phosphorus recycling and photosynthates partitioning in the tropical forage grass, Brachiara hybrid cultivar Mulato compared with rice. Plant Cell Physiol 45:460-469

Rosenblueth M, Martínez-Romero E (2006) Bacterial endophytes and their interactions with hosts. Mol Plant Microbe Interact $19: 827-837$ 
Ruyter-Spira C, Kohlen W, Charnikhova T, van Zeij A, van Bezouwen L, de Ruijter N, Cardoso C, Lopez-Raez JA, Matusova R, Bours R, Verstappen F, Bouwmeester H (2011) Physiological effects of the synthetic strigolactone analog GR24 on root system architecture in Arabidopsis: another belowground role for strigolactones? Plant Physiol 155:721-734

Sato D, Awad AA, Chae SH, Yokota T, Sugimoto Y, Takeuchi Y, Yoneyama K (2003) Analysis of strigolactones, germination stimulants for Striga and Orobanche, by high-performance liquid chromatography/tandem mass spectrometry. J Agric Food Chem 51:1162-1168

Sato D, Awad AA, Takeuchi Y, Yoneyama K (2005) Confirmation and quantification of strigolactones, germination stimulants for root parasitic plants Striga and Orobanche, produced by cotton. Biosci Biotechnol Biochem 69:98-102

Schachtman DP, Shin R (2007) Nutrient sensing and signaling: NPKS. Annu Rev Plant Biol 58:47-69

Smith SE, Read D (2008) Mycorrhizal symbiosis, 3rd edn. Academic Press, London

Soto MJ, Fernández-Aparicio M, Castellanos-Morales V, GarcíaGarrido JM, Ocampo JA, Delgado MJ, Vierheilig H (2010) First indications for the involvement of strigolactones on nodule formation in alfalfa (Medicago sativa). Soil Biol Biochem 42:383-385

Ueno K, Nomura S, Muranaka S, Mizutani M, Takikawa H, Sugimoto Y (2011) Ent-2'-epi-orobanchol and its acetate, as germination stimulants for Striga gesnerioides seeds isolated from cowpea and red clover. J Agric Food Chem 59:10485-10490

Umehara M, Hanada A, Yoshida S, Akiyama K, Arite T et al (2008) Inhibition of shoot branching by new terpenoid plant hormones. Nature 455:195-200

Umehara M, Hanada A, Magome H, Takeda-Kamiya N, Yamaguchi S (2010) Contribution of strigolactones to the inhibition of tiller bud outgrowth under phosphate deficiency in rice. Plant Cell Physiol 51:1118-1126

Williamson LC, Ribrioux SPCP, Fitter HA, Leyser HMO (2001) Phosphate availability regulates root system architecture in Arabidopsis. Plant Physiol 126:875-882

Xie X, Yoneyama K, Kusumoto D, Yamada Y, Yokota T, Takeuchi Y, Yoneyama K (2008a) Isolation and identification of alectrol as $(+)$-orobanchyl acetate, a novel germination stimulant for root parasitic plants. Phytochemistry 69:427-431

Xie X, Yoneyama K, Kusumoto D, Yamada Y, Takeuchi Y, Sugimoto Y, Yoneyama K (2008b) Sorgomol, germination stimulant for root parasitic plants, produced by Sorghum bicolor. Tetrahedron Lett 49:2066-2068

Yoneyama K, Yoneyama K, Takeuchi Y, Sekimoto H (2007a) Phosphorus deficiency in red clover promotes exudation of orobanchol, the signal for mycorrhizal symbionts and germination stimulant for root parasites. Planta 225:1031-1038

Yoneyama K, Xie X, Kusumoto D, Sekimoto H, Sugimoto Y, Takeuchi Y, Yoneyama K (2007b) Nitrogen deficiency as well as phosphorus deficiency in sorghum promotes the production and exudation of 5-deoxystrigol, the host recognition signal for arbuscular mycorrhizal fungi and root parasites. Planta 227: $125-132$

Yoneyama K, Xie X, Sekimoto H, Takeuchi Y, Ogasawara S, Akiyama K, Hayashi H, Yoneyama K (2008) Strigolactones, host recognition signals for root parasitic plants and arbuscular mycorrhizal fungi from Fabaceae plants. New Phytol 179: $484-492$

Yoneyama K, Xie X, Kisugi T, Nomura T, Sekimoto H, Yokota T, Yoneyama K (2011) Characterization of strigolactones exuded by Asteraceae plants. Plant Growth Regul 65:495-504 